\title{
A formação do pedagogo para o ensino da matemática: avanços, desafios e perspectivas
}

\author{
The training of the pedagogue for the Math Education: advances, challenges and \\ perspectives
}

\section{La formación del pedagogo para la enseñanza de las matemáticas: avances, retos y perspectivas}

Mariana Antunes Medeiros de Oliveira ${ }^{1}$

Erika dos Reis Gusmão Andrade ${ }^{2}$

\begin{abstract}
Resumo
Esse artigo intenciona trabalhar a formação de pedagogas para o ensino da matemática, no qual discorreremos sobre o contexto em que está se dando essa formação, as mudanças percebidas, os desafios, avanços e perspectivas. Os participantes da pesquisa foram pedagogas que atuam na docência da educação básica, e que tiveram formação inicial da Universidade Federal do Rio Grande do Norte (UFRN). A metodologia utilizada para a coleta dos dados foram entrevistas semiestruturadas, e para a análise desse material empregamos o eixo interpretativo de Arruda (2005). Em nossas análises trazemos as mudanças percebidas pela instituição formadora no período de 2008 a 2020, dialogando com o discurso dessas profissionais, dados institucionais e as alterações da legislação. Esperamos que nossas reflexões auxiliem para a formação das pedagogas/professoras que ensinam matemática.
\end{abstract}

Palavras-chave: Formação de professores; Pedagogia; Educação Matemática.

\begin{abstract}
This article intends to work on the training of pedagogues for the Math Education, in which we will discuss the context where this training is taking place, the changes alleged, the challenges, developments and perspectives. The participants of the research were pedagogues who work in the teaching of basic education, and who had initial formation at the Federal University of Rio Grande do Norte (UFRN). The methodology used to collect the data was semi-structured interviews, and for the analysis of this material we used the interpretive axis of Arruda (2005). In our analysis we present the changes perceived by the training institution in the period from 2008 to 2020, dialoguing with the speech of these professionals, institutional data and the changes in legislation. We expect that our reflections will help in the reflection for the training of pedagogues/teachers who teach mathematics.
\end{abstract}

Keywords: Teacher training; Pedagogy; Mathematics Education;

\section{Resumen}

\footnotetext{
${ }^{1}$ Pedagoga, Mestra em Educação pelo Programa de Pós-Graduação em Educação (PPGEd/UFRN), tendo como áreas de interesse: formação de professores, ensino de matemática e representações sociais. Integrante do Grupo de Estudos em Educação e Representações Sociais. Professora da Rede Estadual de ensino do Rio Grande do Norte. Natal/RN, Brasil. Email: marianaantunesoliveira@hotmail.com. ORCID: https://orcid.org/0000-00024413-0208.

${ }^{2}$ Professora Titular do Departamento de Fundamentos e Políticas Educacionais do Centro de Educação e Permanente do Programa de Pós-Graduação em Educação da Universidade Federal do Rio Grande do Norte, na Linha de Pesquisa Educação, Práticas Pedagógicas e Currículo. da UFRN. Email: ergandrade@gmail.com. ORCID: https://orcid.org/0000-0002-5296-8481.
} 
Este artículo lleva la intención de trabajar la formación de pedagogas para la enseñanza de las matemáticas, en el que vamos a discurrir acerca del contexto en lo cual se ha dado dicha formación, los cambios observados, los retos, avanzos y perspectivas. Esta investigación tuvo como participantes a las pedagogas que actúan en la docencia de la educación básica, las que tuvieron su formación inicial en la Universidad Federal de Rio Grande del Norte (UFRN). La metodología utilizada para la recolección de datos fue la entrevista semiestructurada, y para el análisis de este material utilizamos el eje interpretativo de Arruda (2005). En nuestro análisis presentamos los cambios observados por la institución formadora en el período de 2008 al 2020, dialogando con el discurso de esas profesionales, datos institucionales y alteraciones de la legislación. Esperamos que nuestras reflexiones ayuden en la formación de pedagogas/profesoras que enseñan matemáticas.

Palabras clave: Formación de Profesores; Pedagogía; Educacion matemática.

\section{Introdução}

A formação na licenciatura em Pedagogia ${ }^{3}$ envolve uma variedade de áreas que contempla os ensinos nos campos de atuação do pedagogo ${ }^{4}$, os fundamentos epistemológicos, sociológicos e filosóficos, a atuação em diferentes funções (professor, coordenador, gestor) e nos diferentes espaços (escolas, hospitais, empresas...). Nesse artigo optamos por aprofundar os aspectos formativos da formação dessa pedagoga/professora para se ensinar matemática nos anos iniciais. Colocando quais são os avanços, desafios e perspectivas percebidas na formação e prática dessas profissionais.

Os dados empíricos que serão aqui expostos foram coletados durante a pesquisa de mestrado de Oliveira (2020), e constituem um recorte do que foi explorado na dissertação. Foram realizadas 20 (vinte) entrevistas semiestruturadas, tendo como critérios para a participação a formação inicial na Universidade Federal do Rio Grande do Norte (UFRN) e período mínimo de 1 (um) ano na docência da educação básica. As participantes foram egressas do Curso de Pedagogia da UFRN no período entre 2008.1 a 2017.2, ou seja, um intervalo temporal de 20 semestres letivos. Sendo 2 (dois) participantes de cada ano

\footnotetext{
${ }^{3}$ A licenciatura em Pedagogia da instituição pesquisada pertence ao departamento de Educação. Os docentes responsáveis pelas disciplinas de Ensino da Matemática possuíam doutorado em Educação. Alguns docentes tinham graduação em Pedagogia e outros em Matemática.

${ }^{4} \mathrm{O}$ pedagogo licenciado em Pedagogia está habilitado a ensinar as disciplinas de Português, Matemática, História, Geografia e Ciências nos Anos Iniciais do Ensino Fundamental.
} 
(vespertino e noturno ${ }^{5}$ ), totalizando 20 entrevistas. São utilizados pseudônimos para garantir o anonimato das professoras.

Optamos pelo gênero feminino para nos remeter às participantes da pesquisa, pois, embora haja alguns homens sendo entrevistados, existe uma expressividade maior no quantitativo de mulheres, caracterizando o grupo como, predominantemente, feminino. $\mathrm{O}$ termo pedagogas/professoras parte do entendimento que o termo pedagoga vem primeiro por ser mais amplo e abranger outras funções, e o termo professora vem junto, para que fique claro que estamos trabalhando apenas com as pedagogas que estão em atividade na docência.

O texto estará dividido em 3 (três) subitens. No primeiro A formação do curso de Pedagogia para se ensinar matemática contextualizamos e descrevemos como está ocorre essa formação inicial pela Instituição de Ensino Superior (IES). O subitem seguinte Desafios e avanços no ensino da matemática discorre com base nos dados, quais são os desafios e avanços mencionados e/ou percebidos por estes docentes, mediante a formação recebida. Por fim, nossas Perspectivas e considerações com a temática, diante dos resultados apresentados.

\section{A formação do curso de pedagogia para se ensinar matemática}

O espaço formativo dentro do currículo do curso de Pedagogia é um campo disputado diante de sua abrangência. Essa é uma questão histórica dos cursos de Pedagogia em geral, não apenas do curso de Pedagogia da UFRN. Gatti (2010), traz diversos aspectos relacionados à formação de professores nos cursos de Pedagogia do Brasil, ressaltando que, a partir da Resolução n.1, de 15/05/2006, as Diretrizes Curriculares Nacionais propõem tais cursos como licenciaturas, saindo do contexto histórico do modelo formativo mais bacharelesco e dando ao curso amplas atribuições.

A autora expõe algumas dessas atribuições no excerto abaixo:

Aplicação ao campo da educação, de contribuições, entre outras, de conhecimentos como o filosófico, o histórico, o antropológico, o ambientalecológico, o psicológico, o linguístico, o sociológico, o político, o econômico, o cultural; englobar (art. $4^{\circ}$, parágrafo único) a formação de habilidades de planejamento, execução, coordenação, acompanhamento e avaliação de tarefas próprias do setor da Educação, de projetos e experiências educativas não escolares; a produção e difusão do

\footnotetext{
${ }^{5}$ No período pesquisado, entre 2008.1 a 2017, o curso de Pedagogia da UFRN não teve turmas no turno matutino.
} 
conhecimento científico-tecnológico do campo educacional, em contextos escolares e não-escolares. O licenciando em pedagogia deverá ainda: estar apto no que é especificado em mais de dezesseis incisos do artigo $5^{\circ}$, inciso IV, do artigo $8^{\circ}$. (GATTI, 2010, p. 1.358).

Pensar o currículo para o curso de Pedagogia em decorrência do grande número de atribuições é, sem sombra de dúvida, um desafio. E esse é um dos motivos pelos quais a Matemática encontra pouco espaço dentro da estrutura curricular. Ainda no tocante ao espaço no currículo, as participantes da pesquisa mencionam que os conteúdos relativos a aprendizagem da língua materna possui maior interlocução, superior número de disciplinas e construção iniciada mais cedo que aqueles relativos ao ensino da Matemática, enfatizando, desde o início do curso, o sentimento de pertença como professor (a) alfabetizador (a). Ao passo que a Matemática estabelece uma relação com as pedagogas/professoras em um momento mais tardio, com a presença de apenas duas disciplinas.

Percebemos o exposto no parágrafo anterior como uma fragilidade que implica, negativamente, no sentimento de pertença desse profissional que ensina Matemática. A fala de uma das participantes, abaixo, remete a esse aspecto:

Engraçado você falando assim, como professora de Matemática, porque eu nunca parei para pensar enquanto professora de Matemática! Porque eu me vejo mais como professora de letramento, tá ligado? Que tá ali para alfabetizar. Eu me vejo mais discutindo assuntos sobre história. Tanto é que a gente vai fazer uma feira de ciências sobre a África, o conteúdo que é de história, mas eu nunca parei para pensar, nunca parei para questionar como é ser professora de Matemática. Tanto é que quando você lançou essa pergunta eu pensei, 'mas ela sabe que eu sou pedagoga, né'?! (HIPÁTIA, 2018)'.

Analisando a evocação acima, podemos fazer duas observações: a primeira acerca desse sentimento de não pertença da pedagoga/professora em relação à Matemática, ao passo que, referente ao ensino da língua materna, tal sentimento é bem mais consistente e solidificado. O currículo possibilita tanto isso quanto a segunda observação, que concerne à afinidade com a Matemática.

Dentro do mesmo grupo encontramos duas visões opostas acerca da formação inicial recebida: um subgrupo que evidencia a consistência e fundamentação recebida durante a formação, apontando a adequação da metodologia e presença de aspectos que eram desconhecidos no ensino da Matemática, tais como o uso de jogos e materiais concretos; o

\footnotetext{
${ }^{6}$ Documento não paginado. Entrevistas orais. Hipátia foi o pseudônimo atribuído pela participante.
} 
outro, traz o discurso oposto, no qual a formação inicial é vista como inconsistente, apresentando lacunas e distanciando-se da prática na sala de aula, e tradicional, sem a devida relação com a infância.

Tal fato desperta a atenção para a existência de dois modelos formativos diferentes e antagônicos dentro de um mesmo curso e instituição. Esses modelos formativos resultam das concepções teóricas e metodológicas utilizadas pelos docentes de Ensino da Matemática, conforme exemplificam as falas das participantes do estudo.

O primeiro modelo, baseado na Pedagogia Tradicional, entende a didática como um conjunto de princípios e regras que regulam o ensino.

Libâneo (1994) descreve as características dessa Pedagogia Tradicional:

A atividade de ensinar é centrada no professor que expõe e interpreta a matéria. Às vezes são utilizados meios como a apresentação de objetos, ilustrações, exemplos, mas o meio principal é a palavra, a exposição oral. Supõe-se que ouvindo e fazendo exercícios repetitivos, os alunos "gravam" a matéria para depois reproduzi-la [...] A matéria de ensino é tratada isoladamente, isto é, desvinculada dos interesses dos alunos e dos problemas reais da sociedade e da vida. O método é dado pela lógica e sequência da matéria, é o meio utilizado pelo professor para comunicar a matéria e não dos alunos para aprendê-la. (LIBÂNEO, 1994, p. 64).

As pedagogas/professoras que passaram por essa concepção tradicional de ensino, durante a graduação no curso de Pedagogia, afirmam que tiveram dificuldade de compreender os conteúdos e transpô-los para a prática. Também revelam que os conteúdos abordados não estavam adequados aos níveis de atuação da pedagoga, revelando muitas lacunas que podem ser superadas em seu processo auto formativo ou em formações continuadas. Algumas participantes pertencentes a esse modelo ficaram mais à vontade para expressar sentimentos sobre isso depois que desligamos o gravador.

Nesse sentido, as pedagogas/professoras que tiveram uma formação contemplada por conhecimentos relativos às novas tendências da Educação Matemática, relacionando-os à aprendizagem na infância, e uma tentativa de interlocução entre teoria e prática, embora disponibilizada em pouco tempo, com os componentes curriculares de Ensino da Matemática, estão mais satisfeitas profissionalmente, mesmo considerando insuficientes os estudos acerca da temática.

Mesmo diante de duas realidades formativas distintas, é comum entre as participantes do grupo ressaltar a necessidade de uma maior relação entre teoria e prática, enfatizando que 
tal relação é capaz de ser um diferencial na formação dos profissionais da área. A baixa incidência dessa associação entre teoria e prática também é mencionada nos estágios supervisionados. A teoria é vista, ainda, como distante da prática em sala de aula. $\mathrm{O}$ diferencial está naquelas profissionais que tiveram alguma experiência de estágio e buscaram, por iniciativa própria, estabelecer essa relação.

Pimenta e Lucena (2006), discorrem sobre a questão dos estágios supervisionados, e expõem que os estágios não podem ser reduzidos a perspectiva da prática instrumental e do criticismo. Nos estágios teoria e prática devem estar imbricados e dar-se como processos simultâneos. Acerca das funções da teoria e da prática nos estágios, as autoras colocam que:

O papel das teorias é o de iluminar e oferecer instrumentos e esquemas para análise e investigação, que permitam questionar as práticas institucionalizadas e de ações dos sujeitos e, ao mesmo tempo, se colocar elas próprias em questionamento, uma vez que as teorias são explicações sempre provisórias da realidade. A prática educativa (institucional) é um traço cultural compartilhado e que tem relação com o que acontece em outros âmbitos da sociedade e de suas instituições. Portanto, no estágio dos cursos de formação de professores, compete possibilitar que os futuros professores se apropriem da compreensão dessa complexidade das práticas institucionais e das ações aí praticadas por seus profissionais, como possibilidade de se prepararem para sua inserção profissional. (PIMENTA; LUCENA, 2006, p. 12).

Sendo assim, é possível entender que os estágios supervisionados constituem espaços que deverão possibilitar o preparo para o exercício profissional de maneira consistente, e articulando teoria e prática. A teoria irá embasar e oferecer instrumentos para a realização da prática, devendo constituir-se num processo retroalimentado e articulado. Devemos salientar, ainda, que algumas instituições privadas de ensino têm formação e metodologia próprias para o ensino da Matemática.

Focando na relação entre teoria e prática, as professoras argumentam:

[...] a graduação precisa oferecer uma... uma... precisa possibilitar esse... esse... a esse aluno do curso de Pedagogia... eu acho que mais... dialogar mais com esses dois campos: a teoria e a prática. Porque, no meu caso, eu acho que ficou mais no campo da teoria. Então, o primeiro desafio é esse. (PITÁGORAS, 2018) ${ }^{7}$.

\footnotetext{
${ }^{7}$ Documento não paginado. Entrevistas orais. Pitágoras e Sr. Cosseno foram os pseudônimos escolhidos pelas participantes.
}

Revista Devir Educação, Lavras, vol.5, n.1, p.3-23, jan.jun/ 2021 
Depois que eu tive acesso à formação acadêmica, eu ressignifiquei. Para mim, ensinar Matemática... Eu ensinava da maneira tradicional. É... Operações fundamentais de forma bem tradicional e, depois da formação acadêmica, eu pude ver esse grande universo que eu deixava de lado e que eu podia trabalhar. A questão dos jogos, a questão do material concreto, do material dourado, eu não utilizava. Então, teve importância para eu pensar, para eu exercer minha docência de outra forma. (SR. COSSENO, 2018).

O modelo formativo e a metodologia adotada pelo docente da academia, segundo nossos dados, pode favorecer ou dificultar a relação entre teoria e prática. O discurso da participante Pitágoras está apoiado em construtos formativos que apontam para uma ampliação dessa relação durante a formação inicial e para uma perspectiva tradicional do ensino.

Já Sr. Cosseno demonstra ter outro tipo de formação, prezando por um modelo dialógico, com teorias e metodologias relacionadas à prática profissional, o ensinar da Matemática para que o professor compreenda a Matemática, o porquê e como ensiná-la. Aparece, nesses discursos, uma Matemática significativa, através da qual o professor tem consciência do quê e do porquê está ensinando.

Sr. Cosseno afirma que a formação acadêmica lhe permitiu sair do modelo tradicional e conhecer outras metodologias de ensino. Ademais, menciona a tendência do uso de jogos e materiais concretos.

A presença de modelos formativos diversos, resultantes de maiores ou menores contribuições para o ensino, é bastante recorrente nas entrevistas. Algumas participantes passaram pelos dois modelos, nas vivências das duas disciplinas do curso voltadas para a área da Matemática, e enfatizam esse comparativo.

A professora Montessori explicita o seguinte:

Na primeira disciplina, eu lembro que... é... Eu realmente tive um pouco de dificuldade, né? Até porque a metodologia da disciplina era mais tradicional, mais focada mesmo na questão do cálculo, daquilo tudo. Mas, no Ensino II, foi que eu comecei a desconstruir essa noção de que a Matemática era difícil! Que era uma coisa impossível de aprender, né? A professora apresentou de uma maneira diferente a Matemática, né? Tanto que mudou a minha percepção da Matemática em si, quanto à forma de ensinar, né? Porque ela trouxe a questão dos jogos, né? Ampliou o conceito de Matemática, e isso foi me ajudando. Foi me ajudando a descontruir aquela ideia que eu tinha, que a Matemática era algo impossível, que era algo difícil e que eu não teria condições de ensinar Matemática, né? Na disciplina de 
Matemática II eu comecei a desconstruir um pouco isso. (MONTESSORI, $2018)^{8}$.

A professora Montessori tanto indica essa presença de modelos formativos distintos como nos faz perceber a possibilidade de obter resultados positivos com o ensino da Matemática, sendo também concebível ressignificar o olhar direcionado à Matemática e apropriar-se de conhecimentos que nos proporcionam ensiná-la em outra perspectiva.

Apresentaremos, no quadro 1, dados sobre os componentes curriculares de Ensino da Matemática e analisaremos as mudanças que têm sido realizadas, relacionando tais elementos com o contexto no qual estão inseridas as participantes. As informações acerca dos componentes curriculares de ensino da Matemática, contidas nos quadros 1, foram retiradas do Sistema Integrado de Gestão e Atividades Acadêmicas (SIGAA/UFRN).

Quadro 1 - Dados sobre os componentes curriculares de Ensino da Matemática

\begin{tabular}{|c|c|c|}
\hline $\begin{array}{l}\text { Código/Ano de } \\
\text { implementação/U } \\
\text { nidade }\end{array}$ & Nome & Ementa \\
\hline $\begin{array}{l}\text { EDU0633/1998/C } \\
\text { CSA } \\
\text { Ou } \\
\text { PEC0633/2011/ } \\
\text { Dep. de Prat. Ed. } \\
\text { e Currículo }\end{array}$ & $\begin{array}{l}\text { O Ensino da Matemática } \\
\text { no } 1^{\circ} \text { grau I - } 60 \mathrm{~h} \\
60 \mathrm{~h} \text { - teóricas } \\
\text { Oh - práticas }\end{array}$ & $\begin{array}{l}\text { A Matemática e a Educação Matemática: conceitos e } \\
\text { linguagem no Ensino Fundamental; metodologia do ensino de } \\
\text { números, geometria e medidas. Materiais didáticos no ensino } \\
\text { de Matemática. }\end{array}$ \\
\hline $\begin{array}{l}\text { EDU0638/1998/C } \\
\text { CSA }\end{array}$ & $\begin{array}{l}\text { O Ensino da Matemática } \\
\text { no } 1^{\circ} \text { grau II }-60 \mathrm{~h} \\
60 \mathrm{~h} \text { - teóricas } \\
0 \mathrm{~h} \text { - práticas }\end{array}$ & $\begin{array}{l}\text { A Matemática e a Educação Matemática: conceitos e } \\
\text { linguagem no Ensino Fundamental; metodologia do ensino de } \\
\text { números, geometria e medidas. Materiais didáticos no ensino } \\
\text { de Matemática. }\end{array}$ \\
\hline EDU1020 & $\begin{array}{l}\text { Ensino da Matemática I } \\
-90 \mathrm{~h}\end{array}$ & $\begin{array}{l}\text { Propostas curriculares e pedagógicas para o ensino da } \\
\text { Matemática na Educação Infantil, anos iniciais do Ensino }\end{array}$ \\
\hline
\end{tabular}

${ }^{8}$ Documento não paginado. Entrevista oral. Montessori foi o pseudônimo escolhido pela participante.

Revista Devir Educação, Lavras, vol.5, n.1, p.3-23, jan.jun/ 2021 


\begin{tabular}{|c|c|c|}
\hline (Inativo) & $\begin{array}{l}60 \mathrm{~h} \text { - teóricas } \\
30 \mathrm{~h} \text { - práticas }\end{array}$ & $\begin{array}{l}\text { Fundamental e Educação de Jovens e Adultos. A Matemática } \\
\text { enquanto objeto sócio-histórico de conhecimento: aspectos que } \\
\text { a constituem, seus usos e funções. Estudo da gênese e do } \\
\text { desenvolvimento do conhecimento numérico. Linguagem } \\
\text { Matemática. Ensino dos sistemas de numeração, números e } \\
\text { operações no campo dos números racionais absolutos. } \\
\text { Metodologias e recursos auxiliares ao ensino e aprendizagem, } \\
\text { planejamento e avaliação no ensino de números. }\end{array}$ \\
\hline $\begin{array}{l}\text { EDU5029/2010/C } \\
\text { CSA }\end{array}$ & $\begin{array}{l}\text { Ensino da Matemática I } \\
-60 \mathrm{~h} \\
30 \mathrm{~h} \text { - teóricas } \\
30 \mathrm{~h} \text { - práticas }\end{array}$ & $\begin{array}{l}\text { Tendências da pesquisa na Educação Matemática para o } \\
\text { ensino e aprendizagem da Matemática na Educação Infantil, } \\
\text { anos iniciais do Ensino Fundamental e Educação de Jovens e } \\
\text { Adultos. O ensino dos sistemas de numeração, números e } \\
\text { operações no campo dos números racionais absolutos. } \\
\text { Conceitos numéricos e linguagem. Metodologias e recursos } \\
\text { auxiliares ao ensino e aprendizagem, planejamento e avaliação } \\
\text { no ensino de números. }\end{array}$ \\
\hline $\begin{array}{l}\text { PEC5029/2011/D } \\
\text { ep. de Prat. Ed. e } \\
\text { Currículo }\end{array}$ & $\begin{array}{l}\text { Ensino da Matemática I } \\
-60 \mathrm{~h} \\
60 \mathrm{~h} \text { - teóricas } \\
0 \mathrm{~h} \text { - práticas }\end{array}$ & $\begin{array}{l}\text { Tendências da pesquisa na Educação Matemática para o } \\
\text { ensino e aprendizagem da Matemática na Educação Infantil, } \\
\text { anos iniciais do Ensino Fundamental e Educação de Jovens e } \\
\text { Adultos. O ensino dos sistemas de numeração, números e } \\
\text { operações no campo dos números racionais absolutos. } \\
\text { Conceitos numéricos e linguagem. Metodologias e recursos } \\
\text { auxiliares ao ensino e aprendizagem, planejamento e avaliação } \\
\text { no ensino de números. }\end{array}$ \\
\hline $\begin{array}{l}\text { EDU1024/Inativo } \\
\text { /CCSA }\end{array}$ & $\begin{array}{l}\text { Ensino da Matemática II } \\
-90 \mathrm{~h} \\
60 \mathrm{~h} \text { - teóricas } \\
30 \mathrm{~h} \text { - práticas }\end{array}$ & $\begin{array}{l}\text { Tendências da pesquisa na Educação Matemática para o } \\
\text { ensino e aprendizagem da Matemática na Educação Infantil, } \\
\text { anos iniciais do Ensino Fundamental e Educação de Jovens e } \\
\text { Adultos. Desenvolvimento das percepções espaço- } \\
\text { geométricas: relações espaciais topológica, projetiva e } \\
\text { euclidiana. O ensino de propriedades de figuras geométricas } \\
\text { planas e tridimensionais; ângulo; simetria; grandezas de } \\
\text { comprimento, área, volume. Metodologias e recursos } \\
\text { auxiliares ao ensino e aprendizagem, planejamento e avaliação } \\
\text { de conceitos geométricos e medidas. }\end{array}$ \\
\hline $\begin{array}{l}\text { EDU5036/2010/C } \\
\text { CSA } \\
\text { Ou } \\
\text { PEC5036/2011/ } \\
\text { Dep. de Prat. Ed. } \\
\text { e Currículo }\end{array}$ & $\begin{array}{l}\text { Ensino da Matemática II } \\
-90 \mathrm{~h} \\
45 \mathrm{~h} \text { - teóricas } \\
45 \mathrm{~h} \text { - práticas }\end{array}$ & $\begin{array}{l}\text { Propostas curriculares e pedagógicas para o ensino da } \\
\text { Matemática na Educação Infantil, anos iniciais do Ensino } \\
\text { Fundamental e Educação de Jovens e Adultos. O ensino de } \\
\text { propriedades de figuras geométricas planas e tridimensionais; } \\
\text { simetria e semelhança; grandezas de comprimento, área, } \\
\text { volume e ângulo; linguagem Matemática. Metodologias e } \\
\text { recursos auxiliares ao ensino e aprendizagem, planejamento e } \\
\text { avaliação de conceitos geométricos e medidas. }\end{array}$ \\
\hline
\end{tabular}

Fonte: OLIVEIRA, 2020, p. 79/80. 


\section{ODEVIR EDUCAÇÃO}

ISSN: 2526-849X

Observando o quadro, notamos que alguns componentes curriculares possuem dois códigos diferentes, sendo um vinculado ao Centro de Ciências Sociais Aplicadas (CCSA) e o outro, ao Departamento de Práticas Educacionais e Currículo do Centro de Educação (CE). Isso ocorreu devido à implantação do Centro de Educação, no qual os componentes curriculares perderam o antigo vínculo com o CCSA e passaram a fazer parte do referido departamento.

As disciplinas de ensino da Matemática efetivadas no modelo 004/94 destinavam a carga horária total do componente curricular à parte teórica. A partir do currículo 01/2009, evidenciamos, mais claramente, nas ementas dos cursos, a preocupação com a relação entre teoria e prática.

Percebemos, então, que, de 2010 em diante, os componentes curriculares voltados para o ensino da Matemática passam a distribuir a carga horária entre parte teórica e prática, levando-nos a inferir que houve a percepção do quanto é necessário trabalhar essa relação.

Das participantes das entrevistas, 60\% são do currículo 004/94. Isso significar dizer que a maioria das pedagogas/professoras da pesquisa cursou os componentes curriculares de ensino da Matemática que previam, segundo o SIGAA, apenas a carga horária teórica. As demais participantes, $40 \%$, cursaram as disciplinas da Matemática já prevendo parte teórica e prática.

Durante o semestre de 2019.1, ao participarmos da atividade de docência assistida em Ensino da Matemática, identificamos que já existem atividades interdisciplinares com outros componentes curriculares e atividades desenvolvidas em escolas.

Quando a formação inicial não apresenta novos elementos e experiências que relacionam teoria e prática, distancia-se das atuais concepções de Educação Matemática, podendo ocorrer a reprodução dos modelos escolares tradicionais de ensino.

Acho que a base que a gente tem quando a gente é criança ajuda mais a gente a ensinar do que o que a gente aprende na faculdade, porque fica muito gravado o que a gente viveu na escola, na infância. Então, mesmo que a gente tenha visto na faculdade, foi só um ano, dois semestres, e a escola é o que grava mais. Foi 8 anos na escola. (CÁlCULO, 2019) ${ }^{9}$.

A fala acima remete a um discurso distante do contexto profissionalizado, embora, no decorrer da entrevista, a participante mencione aspectos oriundos de sua formação que

\footnotetext{
${ }^{9}$ Documento não paginado. Entrevistas orais. Cálculo foi o pseudônimo escolhido pela participante.
} 
contribuíram para sua prática, afirmando o seguinte: "passar pelo processo na faculdade, entender de que eles precisavam de um material de apoio, modificou minha forma de fazer, porque, antes disso, eu fazia de qualquer jeito" (CÁLCULO, 2019).

Com base no discurso de Cálculo, compreendemos que ninguém passa pelo processo formativo e sai da mesma forma como entrou. As vivências do percurso de formação inicial, de alguma forma, favorecem o processo de reconstrução do fazer docente. Sendo assim, a preocupação emergente está ligada ao modo que ocorre esse processo formativo, a saber, de forma profissional e consciente pautado na dialogicidade, favorecendo um movimento circular e retroalimentado entre docente e discente na formação inicial.

As pedagogas/professoras que passaram por uma formação inicial baseada no modelo tradicional de ensino mencionam as seguintes consequências: falta de compreensão do que é ensinar Matemática; baixo entendimento das aulas do ensino da Matemática; pouca significância e quantidade de conteúdos na formação inicial; carência de mais diálogo e sensibilidade na formação inicial; necessidade de ressignificar a docência no processo formativo; mudanças curriculares e variação nas estratégias docentes durante a graduação.

Quando a formação inicial não consegue estabelecer a relação entre teoria e prática no ensino da Matemática, pode ocorrer a seguinte repercussão: as pedagogas/professoras, ao passarem pela formação, se apropriam de conhecimentos teóricos. Contudo, o fato de não saber transpor isso para a prática faz com que ancorem o fazer docente nos modelos escolares vivenciados por elas enquanto alunas da educação básica.

Monteiro (2016) apresenta, algumas reflexões sobre as mudanças ocorridas na formação inicial docente no que se refere à relação teoria e prática. O diálogo com essa autora nos auxilia na compreensão das razões que motivam a existência dessas dificuldades na relação teoria e prática bem como na identificação das mudanças que têm oportunizado avançar e minimizar essa problemática.

O surgimento de novos paradigmas vem a modificar esse entendimento. Sobre essas mudanças de pensamento, Monteiro (2016) explica:

Discute-se a formação, as práticas pedagógicas e a construção do conhecimento na perspectiva da formação inicial e/ou continuada, articulada com a prática social de ensinar, buscando superar os vestígios herdados da racionalidade técnica. Assim, verifica-se, na atual literatura sobre esta temática, que a formação não pode ser mais limitada por esse modelo, uma vez que essa não pode ser desvinculada de uma construção social. (MONTEIRO, 2016, p. 5). 


\section{OO DEVIR EDUCAÇÃO}

ISSN: 2526-849X

Os novos movimentos, segundo a autora, vêm teorizando e identificando práticas pedagógicas que buscam romper com essa lógica linear de conceber o conhecimento e permitem o desenvolvimento de uma práxis compreendida como uma atividade articulada entre teoria e prática, em que esses conhecimentos sejam capazes de atuar, de forma consciente, para a modificação da realidade.

\section{Desafios e avanços no ensino da matemática}

Os avanços globais no ensino da Matemática são historicamente recentes e a exigência do curso superior, por parte da legislação, foi estabelecida pela LDB 9.394/1996. Desse modo, o primeiro desafio consiste em explorar mais esse campo, trazendo pesquisas que possam contribuir para o ensino da Matemática pela pedagoga/professora. É nossa intenção colaborar, incentivando o surgimento de estudos afins com o intuito de ressignificar esse fazer docente.

No que se refere à carga horária total do curso de Pedagogia, tivemos participantes de dois modelos curriculares: o modelo 004/94, com carga horária total de 2.580 horas, e o modelo 01/2009, com 3.220 horas. Em ambas as matrizes curriculares, aparecem duas disciplinas destinadas à Matemática: "Ensino de Matemática I", com carga horária de 60 horas, e "Ensino de Matemática II", com carga horária de 90 horas, juntas totalizando 150 horas durante todo o curso.

No ensino da Matemática, a formação está reduzida a esses dois componentes curriculares cursados nos últimos períodos da graduação em Pedagogia. Defendemos que repensar esse contexto formativo, promovendo um maior diálogo da Matemática durante o curso, permitirá que as pedagogas/professoras tenham mais oportunidades de superar suas dificuldades no contexto do ensino da Matemática, maior aproximação com o campo e o sentimento de pertença como professora que ensina Matemática.

A disposição das componentes curriculares na área da Matemática apenas no final do curso fragiliza a relação da pedagoga/professora com a Educação Matemática. Ademais, durante o percurso formativo desses profissionais, são percebidas dificuldades com os conteúdos específicos da Matemática que não devem ser negligenciadas, pois podem implicar em consequências negativas para o ensino. 
Ainda no que diz respeito ao conteúdo específico da Matemática, é fundamental que a pedagoga/professora disponha com propriedade desse conhecimento matemático, sendo capaz de utilizar os conteúdos pedagógicos para construir um ensino significativo.

Nossos dados, assim como a pesquisa de Nacarato; Mengali; Passos (2009) mostram que pedagogas/professoras carregam, em sua história de vida escolar, uma relação negativa com a Matemática, apresentando dificuldades com tais conteúdos. Analisando o que foi posto, percebemos a necessidade de repensar essa questão no processo formativo do profissional que ensina Matemática, tendo em vista a priorização da parte metodológica nos cursos de Pedagogia.

Na temática do conteúdo específico, Candau (1997) evidencia que "a competência básica de todo e qualquer professor é o domínio do conteúdo específico. Somente a partir deste ponto é possível construir a competência pedagógica" (CANDAU, 1997, p.46). No contexto de formação desse profissional que também ensina Matemática e é consciente dessas lacunas no conteúdo específico, entendemos como imprescindível ressignificar o processo formativo, levando em consideração as especificidades da Educação Matemática.

Os resultados alcançados com a aprendizagem dos estudantes também constituem um desafio e uma preocupação. O Sistema de Avaliação da Educação Básica (SAEB) realiza avaliações periódicas para monitorar a qualidade da educação no Brasil. O conhecido Índice de Desenvolvimento da Educação Básica (IDEB) é constituído da seguinte forma: “os resultados de aprendizagem dos estudantes apurados no SAEB, juntamente com a taxa de aprovação, reprovação e abandono apurada no censo escolar”. (BRASIL, 2018) ${ }^{10}$.

Os dados do SAEB (2017) relativos ao ensino da Matemática de alunos cursando o $5^{\circ}$ ano revelaram que o Rio Grande do Norte apresenta o quarto índice mais baixo em nível de Brasil.

Ortigão (2008), aborda as avaliações dos sistemas educacionais e a avaliação do currículo. Dentro do primeiro tipo de avaliação, a autora faz uma análise em relação ao estilo pedagógico e, utilizando resultados do SAEB 2001, afirma que ao enfatizar a resolução de problemas no ensino, os alunos tendem a apresentar melhores desempenhos na disciplina de Matemática. Conclui, por conseguinte, que:

[...] enfatizar resolução de problemas em sala de aula resulta em uma melhor apropriação do conhecimento de Matemática pelos alunos. No entanto, esse

\footnotetext{
${ }^{10}$ Citação retirada de documento eletrônico que não possui paginação.
} 
conhecimento não é apropriado por todos da mesma forma - os alunos que apresentam nível econômico acima da média da escola beneficiam-se mais, obtendo melhores resultados, comparativamente aos seus colegas com nível socioeconômico mais baixo. (ORTIGÃO, 2008, p. 87).

Em relação a esses dois aspectos, a autora apresenta em suas conclusões a percepção da importância de "trazer para a formação docente a discussão sociológica imbricada na política educacional, além da discussão Matemática e pedagógica”. (ORTIGÃO, 2008, p. 95).

Dessa forma, observamos que o processo de reflexão acerca dos resultados das avaliações nacionais precisa considerar tais aspectos, de forma que o indicador numérico possa apontar as reais causas desses índices.

O Brasil vem, ao longo dos anos, criando políticas públicas com o objetivo de melhorar os resultados no campo educacional como um todo, não apenas na Matemática. Dentre elas, podemos citar: o Ensino Fundamental de 9 anos e o Plano Nacional de Educação (PNE).

A LDB 9.394/1996 sinalizou a criação do ensino obrigatório de 9 anos de duração ao definir a idade de seis anos como ponto inicial dessa etapa do ensino. A decisão tornou-se meta da educação nacional pela Lei 10.172/2001, que aprovou o PNE. Dando continuidade a esse direcionamento, a Lei $\mathrm{n}^{\circ}$ 11.274, de 6 de fevereiro de 2006, instituiu o Ensino Fundamental de 9 anos de duração com a inclusão das crianças de seis anos de idade.

Tais leis visam a inclusão da criança um ano mais cedo na escola. O documento "Ensino Fundamental de nove anos: orientações para a criança de seis anos de idade" menciona resultados de estudos relevantes para justificar que "quando as crianças ingressam na instituição escolar antes dos sete anos de idade, apresentam, em sua maioria, resultados superiores em relação àquelas que ingressam somente aos sete anos”. (BRASIL, 2007, p. 5). Dentre os estudos citados pelo documento está o SAEB 2003.

O PNE é constituído como uma exigência constitucional com periodicidade decenal, estabelecendo planos plurianuais como referência. O PNE apresenta metas nacionais que devem implicar em políticas públicas realizadas de forma articulada entre os entes federativos, caracterizando-se como mais uma ação na tentativa de equidade e qualidade da educação.

Essas são algumas das políticas públicas que, embora não estejam especificamente relacionadas ao ensino da Matemática, dão contribuições à melhoria do ensino em um contexto geral. 
Outros tipos de avanços podem ser percebidos em projetos que visam estabelecer relação com a docência em um contexto de formação inicial, construindo resultados positivos. Desse modo, evidenciamos a importância da investigação para a formação desse profissional, contribuindo com o processo formativo de um professor reflexivo e investigativo que, ao longo das problemáticas oriundas da carreira docente, estuda, pesquisa, discute, problematiza e reflete sobre estratégias eficazes para a solução de situações que possam emergir em sua prática. Uma vez desenvolvida, essa postura poderá acompanhar esse profissional ao longo de sua carreira,

No contexto da UFRN, observamos que o Programa Institucional de Bolsas de Iniciação à Docência (PIBID) de Pedagogia promove essa interlocução entre universidade e escola. Segundo Andrade; Melo (2017), o programa apresenta os seguintes pilares:

\begin{abstract}
Incentivar a formação de docentes em nível superior para a educação básica; contribuir para a valorização do magistério; elevar a qualidade da formação inicial de professores nos cursos de licenciatura, promovendo a integração entre educação superior e educação básica; inserir os licenciandos nos cotidianos das escolas da rede pública de educação, proporcionando-lhes oportunidades de criação e participação em experiências metodológicas, tecnológicas e práticas docentes de caráter inovador e interdisciplinar que busquem a superação de problemas identificados no processo de ensinoaprendizagem; incentivar escolas públicas de educação básica, mobilizando seus professores como co-formadores [sic] dos futuros docentes e tornandoos protagonistas nos processos de formação inicial para o magistério; e, ainda, contribuir para a articulação entre teoria e prática, necessária à formação dos docentes, elevando a qualidade das ações acadêmicas nos cursos de licenciatura. (ANDRADE; MELO, 2017, p. 145/146).
\end{abstract}

Percebemos, através do excerto acima, que o PIBID possibilita a interlocução entre teoria e prática, a relação direta entre universidade e escolas bem como práticas docentes inovadoras e interdisciplinares que buscam a superação dos problemas identificados nas escolas de atuação dos pibidianos. Entretanto, nossos sujeitos de pesquisa participantes do PIBID afirmaram que seus projetos no PIBID focavam mais no processo de aprendizagem da língua materna. Somente um entrevistado revelou ter incluído a Matemática em uma perspectiva interdisciplinar, os demais afirmaram não contemplar a Matemática em seus projetos.

Evidenciando que os projetos de atuação dos pibidianos emergiam da realidade na qual estavam inseridos, parece necessária a investigação mais aprofundada para saber a razão da pouca expressividade da Matemática no diagnóstico de problemas das escolas. A inclusão 
da Matemática, numa perspectiva interdisciplinar ou transdisciplinar, poderia oportunizar essa interlocução da Matemática na relação teoria e prática, permitindo o desenvolvimento do ensino da área.

Outro recurso que tem alcançado resultados positivos é o estudo de grupo. Ferreira (2008) relata uma experiência envolvendo pesquisadoras, professores/alunos (da especialização) e alunos da licenciatura. Os encontros de leitura, discussão de textos e preparação de atividades aconteciam semanalmente.

A autora assevera que "Concluindo o primeiro curso, ao final de 2003, era perceptível uma ampliação dos saberes de todos os participantes. Entretanto, o processo de aprendizagem e mudança não ocorreu da mesma forma para todos". Mais uma vez, é perceptível a relevância do estabelecimento dessa ponte entre universidade e escola para a aprendizagem e o exercício profissional qualificado.

O programa Observatório da Educação (OBEDUC), também constituiu uma política pública que contribui para a formação dos professores, e para a interlocução entre as instituições formadoras e escolas. O INEP afirma que o programa tem como objetivo:

Estimular o crescimento da produção acadêmica e a formação de recursos humanos pós-graduados, nos níveis de mestrado e doutorado, por meio de financiamento específico. O crescimento da produção acadêmica e a formação de recursos humanos pós-graduados, nos níveis de mestrado e doutorado. (BRASIL, 2015) ${ }^{11}$.

Hanita (2016), afirma que o OBEDUC se constitui como um espaço formativo e que sua proposta é mais do que somente a formação de pós-graduados. A autora discute e fornece dados acerca do OBEDUC, explica que o programa investe nessa articulação com a educação básica, licenciatura e pós-graduação, através de projetos que aliem o conhecimento teórico a prática docente.

Outra informação de relevância, dada através do material de análise de Hanita (2016), acerca do OBEDUC foi:

A área mais expressiva em relação às demais áreas nos projetos aprovados nos editais de 2010 e 2012 é a matemática. Nesse sentido, nota-se a OBEDUC proporciona contribuições para a educação matemática e para o desenvolvimento profissional docente de professores que ensinam matemática. (HANITA, 2016, p. 88).

\footnotetext{
${ }^{11}$ Citação retirada de documento eletrônico que não possui paginação.
} 
A informação trazida por Hanita (2016) tem importância, pois, nos faz perceber que já existem projetos e políticas públicas focadas na formação docente, e trabalhando nessa perspectiva integradora com as instituições escolares. Também nos faz perceber o crescimento dado na área da educação Matemática.

Elaboramos duas figuras para sintetizar os desafios e avanços para o ensino da Matemática que foram discutidos neste item. A figura 2 aborda os desafios e a figura 3, os avanços com o ensino da Matemática na perspectiva da pedagoga/professora.

Figura 2 - Desafios das pedagogas/professoras para o ensino da Matemática

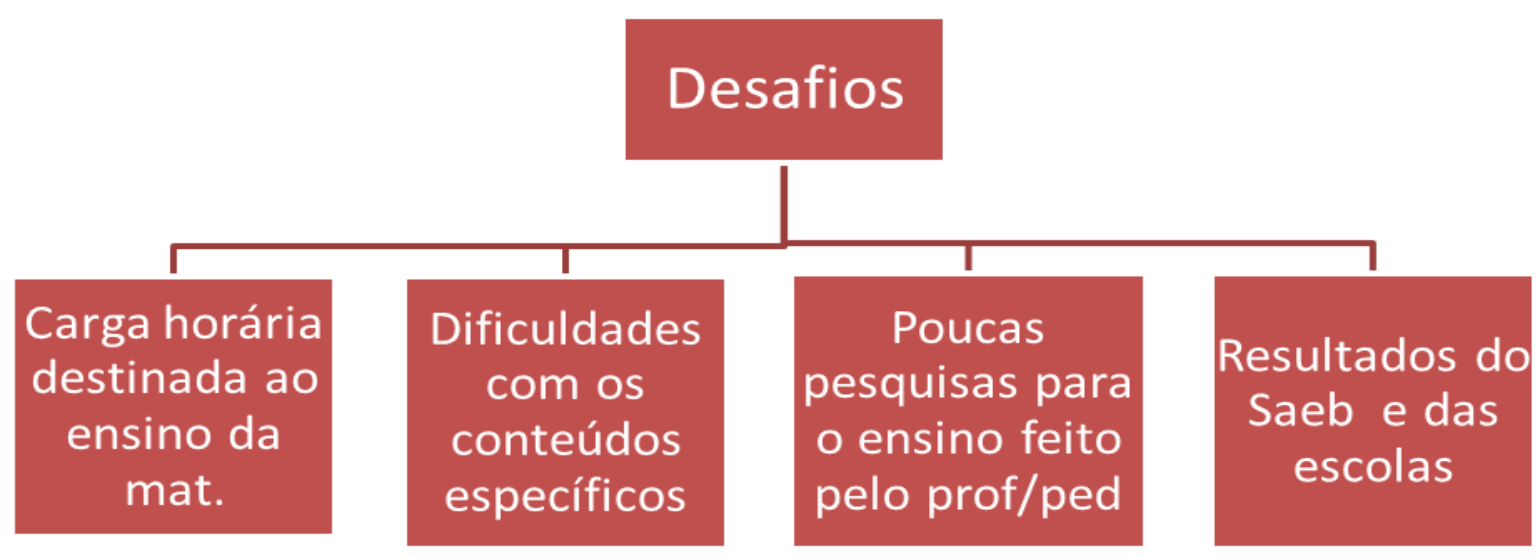

Fonte: Oliveira, 2020, p.45.

A literatura da área e os dados de nossa pesquisa nos levaram ao encontro dos desafios encontrados. A carga horária destinada ao ensino da Matemática no curso de formação inicial não é suficiente para trabalhar todos os aspectos demandados pelas pedagogas/professoras. Existe, por parte da maioria das pedagogas, dificuldades em dominar os conteúdos específicos da Matemática. Essa construção vem desde a escolarização na educação básica, portanto, ao iniciarem sua formação inicial, as professoras já possuíam lacunas relativas às especificidades da área. A maior parte das pesquisas destinadas ao ensino da Matemática tem como foco o licenciado em Matemática, tornando ínfima a parcela de estudos destinados à pedagoga/professora que ensina Matemática.

Os resultados alcançados com a Matemática na educação básica são ruins nos sistemas de avaliações nacionais, e nas escolas, a reprovação e a repetência nos $4^{\circ}$ e $5^{\circ}$ anos dos anos iniciais são preocupantes. 


\section{OO DEVIR EDUCAÇÃO \\ ISSN: 2526-849X}

Após sintetizar os desafios, vamos apresentar o que as pesquisas indicam como ações facilitadoras do ensino da Matemática e o que consideramos como avanços para esse ensino.

Figura 3 - Avanços das pedagogas/professoras no ensino da Matemática

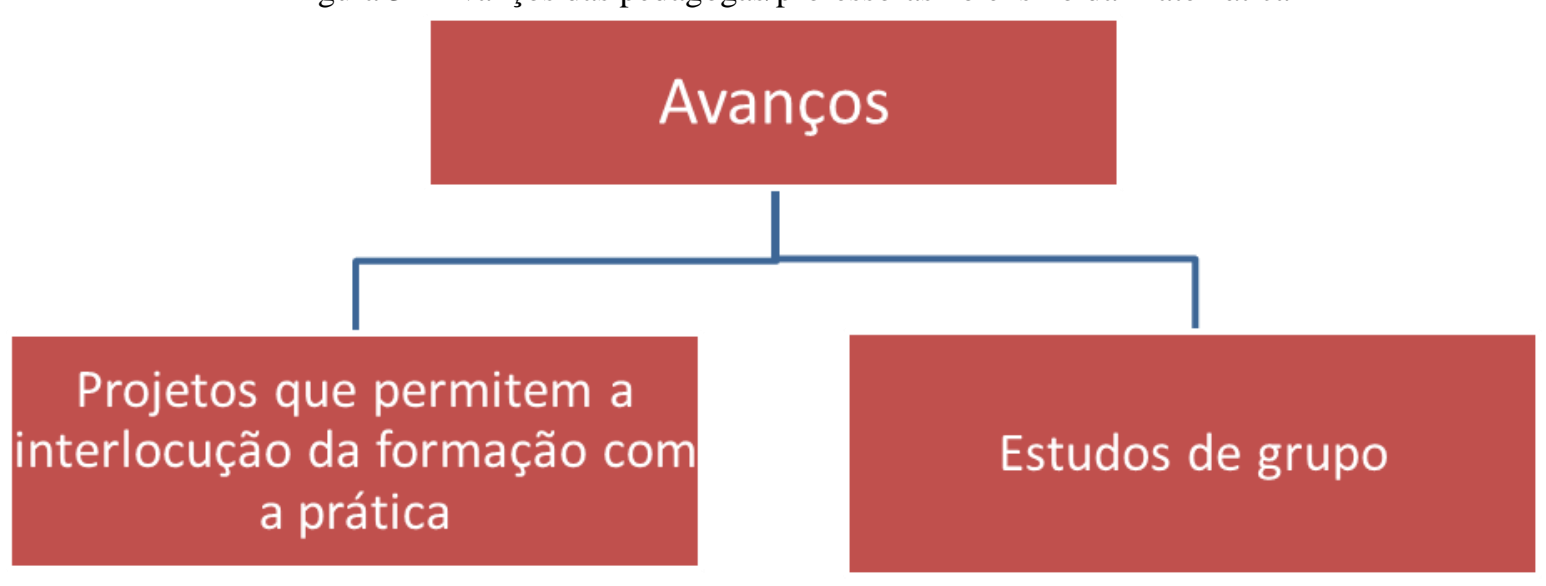

Fonte: Oliveira, 2020, p.46.

Todos os projetos que auxiliam a interlocução da formação com a prática têm apresentado resultados positivos. Observamos que as pesquisas oportunizam a relação entre teoria e prática, e o diálogo entre universidades e escolas avoca a melhoria do ensino. Os estudos de grupo, sejam eles oportunizados pelas instituições escolares ou instituições formadoras, também propiciam significativos avanços para o ensino da Matemática.

\section{Perspectivas e considerações}

Ao longo desse artigo apresentamos como se deu historicamente o processo formativo para o ensino da matemática no Curso de Pedagogia da UFRN, e as mudanças feitas pela IES com o intuito de progredir com o ensino da matemática feito por essas professoras nos anos iniciais da educação básica.

Os dados empíricos, e as pesquisas feitas por outros pesquisadores, nos indicam como desafios para o ensino da matemática: a carga horária destinada ao ensino da matemática, as dificuldades apresentadas pelas pedagogas/professoras com os conteúdos específicos da matemática, as poucas pesquisas destinadas a formação de pedagogas para o ensino da matemática e resultados insatisfatórios com a matemática nas escolas e nos indicadores avaliativos nacionais. 
São percebidos muitos avanços no ensino da matemática quando existem projetos que articulam a formação docente com a prática escolar, contando com participação dos docentes e licenciandos vinculados a universidade e dos professores que estão nas redes de ensino. Os estudos de grupo, seja entre profissionais que compõem a escola, ou destes profissionais com os integrantes da IES, dão contribuições para a formação docente e repercutem positivamente na aprendizagem dos estudantes.

Iniciativas tomadas pela instituição formadora, como: determinar carga horária prática nas disciplinas de ensino da matemática, construção de laboratórios, trabalhos interdisciplinares com outros ensinos, projetos de interlocução com as instituições escolares, metodologias que trabalham as dificuldades das licenciandas com os conteúdos específicos da matemática, e o trabalho com as tendências da educação matemática são ações que nos trazem uma perspectiva positiva de elementos que auxiliam na transposição das dificuldades apresentadas por estas profissionais, descritas detalhadamente na dissertação de mestrado de Oliveira (2020).

Tais mudanças são historicamente muito recentes. $\mathrm{O}$ aumento da carga horária prática foi determinada pelas Diretrizes Curriculares em 2015. A maior parte dessas mudanças têm sido apresentadas nos últimos 5 (cinco) anos. Faz-se necessário mais tempo para que se possam avaliar melhor os impactos de tais mudanças. E ter a clareza também que ainda existem dificuldades a serem superadas, por exemplo, o aumento da carga horária prática é um avanço, mas não garante a interlocução entre teoria e prática. É fundamental que se observem a repercussão dessas inserções e que as se deem continuidade as pesquisas na área de formação de professores que ensinam matemática.

\section{Referências}

ANDRADE, Erika dos Reis Gusmão; MELO, Elda Silva do Nascimento. Refletindo sobre a prática pedagógica no PIBID/Pedagogia - Natal da UFRN. In: Compartilhando saberes na construção da docência no PIBID/UFRN. Organizadores: Lucrécio de Araújo Sá Júnior, Cynara Teixeira Ribeiro e Marta Aparecida Garcia Gonçalves - Natal: EDUFRN, 2017. p. $143-162$.

ARRUDA, Ângela. Despertando do pesadelo: a interpretação. In: Perspectivas Teóricometodológicas em Representações Sociais. / Antonia Silva Paredes Moreira org. - João Pessoa: UFPB/ Editora universitária, 2005. p. 229 - 258.

BRASIL. Lei $\mathrm{n}^{\circ} 11.274$ de 06 de fevereiro de 2006. Altera a redação dos arts. 29, 30, 32 e 87 da Lei $n^{\circ}$ 9.394, de 20 de dezembro de 1996, que estabelece as diretrizes e bases da 
educação nacional, dispondo sobre a duração de 9 (nove) anos, para o Ensino Fundamental, com matrícula obrigatória a partir dos 6 (seis) anos de idade. Brasília [2006]. Disponível em: http://www.planalto.gov.br/ccivil_03/_ato20042006/2006/lei/111274.htm. Acesso em: 25 dez. 2019.

BRASIL. Lei $n^{\circ} 10.172$ de 09 de janeiro de 2001. Aprova o Plano Nacional de Educacional de Educação e dá outras providências. Brasília [2001]. Disponível em: http://www.planalto.gov.br/ccivil_03/leis/leis_2001/110172.htm. Acesso em: 25 dez. 2019.

BRASIL. Lei nº.394, de 20 de dezembro de 1996. Estabelece as Diretrizes e Bases da Educação Nacional. Brasília [1996]. Disponível em: http://www.planalto.gov.br/ccivil_03/leis/19394.htm. Acesso em: 14 out. 2019.

BRASIL. Observatório da Educação. http://inep.gov.br/observatorio-da-educacao. Acesso em: 16 abr. 2020.

BRASIL. Resultados do Saeb 2017. https://medium.com/@inep/resultados-do-saeb-2017f471ec72168d. Acesso em: 16 ago. 2019.

BRASIL. Resolução $\mathbf{N}^{\mathbf{0}} \mathbf{2}$ de $\mathbf{1}^{\mathbf{0}}$ de julho de 2015. Define as Diretrizes Curriculares Nacionais para a formação inicial em nível superior (cursos de licenciatura, cursos de formação pedagógica para graduados e cursos de segunda licenciatura) e para a formação continuada. Brasília [2015]. Disponível em: http://portal.mec.gov.br/docman/agosto-2017pdf/70431-res-cne-cp-002-03072015-pdf/file. Acesso em: 01 abr. 2020.

CANDAU, Vera Maria. Magistério: construção cotidiana. Petrópolis: Vozes, 1997.

CURI, Edda. Análise de propostas presentes no material de Matemática do PECUniversitário, à luz de resultados de investigações e teorias sobre formação de professores. In: A formação do professor que ensina Matemática: perspectivas e pesquisas/ organizado por Adair Mendes Nacarato e Maria Auxiliadora Vilela Paiva. - 1. Ed. 1. Reimp. - Belo Horizonte: Autêntica, 2008. p. 61 - 76.

FERREIRA, Ana Cristina. O trabalho colaborativo como ferramenta e contexto para o desenvolvimento profissional: compartilhando experiências. In: A formação do professor que ensina Matemática: perspectivas e pesquisas/ organizado por Adair Mendes Nacarato e Maria Auxiliadora Vilela Paiva. - 1. Ed. 1. Reimp. - Belo Horizonte: Autêntica, 2008. p. 149 $-166$.

GATTI, Bernardete A. Formação de professores no Brasil: características e problemas. Educ. Soc., Campinas, v.31, $\mathrm{n}^{\mathrm{o}} 113$, p. 1355-1379, out.-dez. 2010. Disponível em http://www.cedes.unicamp.br

HANITA, Marília Yuka. Programa Observatório da Educação e desenvolvimento profissional de professores iniciantes: um estudo a partir das produções da educação matemática. 2016. Dissertação (Mestrado em Educação) - Universidade Federal de São Carlos, campos Sorocaba, Sorocaba. 
LIBÂNEO, José Carlos. Didática. São Paulo: Cortez, 1994. (Coleção magistério. Série formação do professor).

MONTEIRO, Francisca Ocilma Mendes. Relação teoria e prática na formação docente: subsídios de inovação. Criar Educação, Criciúma, v. 6, nº 1, julho/novembro 2016. - PPGE UNESC.

NACARATO, Adair Mendes. A Matemática nos anos iniciais do Ensino Fundamental: tecendo fios do ensinar e do aprender/ Adair Mendes Nacarato, Brenda Leme da Silva Mengali, Carmem Lúcia Brancaglion Passos. - Belo Horizonte: Autêntica Editora, 2009. (Tendências em Educação Matemática).

OLIVEIRA, Mariana Antunes Medeiros de. As Representações Sociais das pedagogas/professoras sobre ensinar matemática. 27/02/2020. 158 f. Dissertação (Mestrado em Educação) - Universidade Federal do Rio Grande do Norte, Natal, 2020.

ORTIGÃO, Maria Izabel Ramalho. Avaliação e Políticas Públicas: possibilidades e desafios para a Educação Matemática. Bolema, Rio Claro (SP), Ano 21, nº 29, 2008, p. 71 - 98.

PIMENTA, Selma Garrido; LIMA, Maria Socorro Lucena. Estágio e docência: diferentes concepções. Revista Poíesis, v. 3, n. 3 e 4. 2005/2006. p. 5 - 24. Disponível em: https://www.researchgate.net/publication/271147223_estagio_e_docencia_diferentes_concepc oes. Acesso em: 20 de abril de 2020.

Recebido em 04/12/2020

Aprovado em 19/04/2021 